\title{
Efeito do nitrogênio e do lodo de esgoto nos fatores produtivos do feijoeiro ${ }^{1}$
}

\author{
Thomaz Figueiredo Lobo ${ }^{2 *}$, Helio Grassi Filho ${ }^{2}$, Leonardo Theodoro Büll ${ }^{2}$
}

\section{RESUMO}

A disposição final do lodo de esgoto vem se caracterizando como um dos problemas ambientais urbanos mais relevantes da atualidade e que cresce diariamente tanto nos países desenvolvidos quanto nos em desenvolvimento, como reflexo da ampliação das redes de coleta e incremento dos níveis de tratamento. O objetivo deste trabalho foi verificar o efeito da aplicação de lodo de esgoto e de adubação química de $\mathrm{N}$ nos fatores produtivos do feijoeiro. O lodo de esgoto compostado foi aplicado em dezembro de 2007, em feijão-comum cultivado em sistema de semeadura direta. Foi adotado o delineamento experimental em blocos casualizados, constituídos por seis tratamentos e quatro repetições, assim definidos: T0 - sem adubação nitrogenada; T1 - adubação química nitrogenada de acordo com o recomendado para a cultura; T2 - 50\% adubação nitrogenada proveniente do lodo de esgoto e 50\% em forma mineral; T3 - $100 \%$ adubação nitrogenada proveniente do lodo de esgoto; T4 - 150\% adubação nitrogenada proveniente do lodo de esgoto e T5 - 200\% adubação nitrogenada proveniente do lodo de esgoto. O aumento da dose de lodo de esgoto promoveu o incremento no número de vagens, rendimento de matéria seca, rendimento de grãos e na massa de 1.000 grãos.

Palavras-chave: sustentabilidade, rendimento e matéria orgânica.

\section{ABSTRACT}

\section{Effect of nitrogen and sewage sludge on yield components of common bean}

The final disposal of sewage sludge has become one of the most important urban environmental problems. The volume of this waste is growing daily in both developed and developing countries, reflecting the expansion of collection networks and increased levels of treatment. The objective of this study was to investigate the effect of sewage sludge and $\mathrm{N}$ chemical fertilizers on bean yield components. Composted sewage sludge was applied in December 2007 on common bean grown in no-tillage system. The experiment was arranged in a randomized block design, consisting of 6 treatments and 4 replicates defined as follows: T0 - no nitrogen fertilization; T1 - mineral nitrogen fertilizer according to the recommendations for the crop; T2 - 50\% nitrogen fertilizer from sewage sludge and 50\% in the mineral form; T3 $100 \%$ nitrogen derived from sewage sludge; T4 - 150\% nitrogen derived from sewage sludge; T5 - $200 \%$ nitrogen derived from sewage sludge. Increasing the dose of sewage sludge promoted an increase in the number of pods, dry matter yield, grain yield and 1000 grain mass.

Key words: sustainability, efficiency and organic matter.

\footnotetext{
Recebido para publicação em 30/11/2010 e aprovado em 14/12/2011

${ }^{1}$ Este trabalho faz parte da tese de doutorado do primeiro autor.

${ }^{2}$ Engenheiros-Agronômos, Doutores. Departamento de Recursos Naturais e Ciência do Solo, Universidade Estadual Paulista Júlio de Mesquita Filho - FCA, Rua Jorge Barbosa de Barros, 573, Jardim Paraíso, 18610-500, Botucatu, São Paulo, Brasil. thomaz.lobo@superig.com.br, heliograsi@fca.unesp.br, bull@fca.unesp.br (*autor para correspondência)
} 


\section{INTRODUÇÃO}

A disposição final do lodo de esgoto vem se caracterizando como um dos problemas ambientais urbanos mais relevantes da atualidade, e que cresce diariamente tanto nos países desenvolvidos quanto naqueles em desenvolvimento, como reflexo da ampliação das redes de coleta e incremento dos níveis de tratamento (Pegorini et al., 2003).

O uso agrícola do lodo de esgoto como adubo orgânico é considerado hoje como alternativa promissora de disposição final deste resíduo, devido a sua sustentabilidade; ou seja, com a sua utilização pode-se diminuir a adubação mineral e fornecer matéria orgânica (Rocha, 1998).

A utilização de lodo de esgoto é uma prática altamente promissora para o desenvolvimento sustentável de sistemas agrícolas. No entanto, normas rígidas devem ser seguidas para a sua utilização, visando minimizar o impacto desta prática no ambiente como a norma técnica P4.240 (Conama, 2006).

O Nitrogênio contido no lodo de esgoto poderá restringir a taxa de aplicação mais do que teores de metais pesados, devido à mineralização de sua forma orgânica e subseqüente à lixiviação de nitrato (Oliveira, 2000), quando aplicado em doses acima de 50 ton $\mathrm{ha}^{-1}$ ano $^{-1}$, ou equivalente em $\mathrm{N}$, acima de $300 \mathrm{~kg}^{-1} \mathrm{ha}^{-1} \mathrm{ano}^{-1}$. A maioria dos nutrientes do lodo está na forma orgânica, como é destacado por Sabey (1980) e Munhoz (2001), tendo apenas cerca de 30 a $50 \%$ do $\mathrm{N}$ total em formas prontamente aproveitáveis pelas plantas no primeiro ano. Segundo Boeira (2004), o lodo de esgoto pode liberar na solução do solo grande quantidade de $\mathrm{N}$ mineral nos primeiros dias após a aplicação, se houver condições propícias para a mineralização da matéria orgânica.

No Brasil, a disposição final do lodo geralmente é o aterro sanitário. Alem do alto custo, que pode chegar a $50 \%$ do custo operacional de uma Estação de Tratamento de Esgotos (ETE), a disposição de um resíduo com elevada carga orgânica no aterro agrava ainda mais o problema com o manejo do lixo urbano. Em países da Europa e América do norte, o lodo geralmente é incinerado, depositado em aterros sanitários ou utilizado em áreas agrícolas, dependendo das características do resíduo. Na maioria dos países existem normas que regulamentam o destino do lodo, garantindo uma disposição segura. A adição ao solo parece ser a melhor opção do ponto de vista econômico e ambiental, uma vez que apresenta o menor custo e promove a reciclagem de nutrientes (Betiol \& Camargo, 2006).

O Nitrogênio é um nutriente fundamental para a cultura do feijoeiro, apresentando alta mobilidade no sistema solo-planta-atmosfera, sendo perdido facilmente por volatilização ou lixiviação. Além disso, os adubos nitrogenados têm baixa eficiência de aproveitamento e alto custo de produção, o que permite considerar que sua utilização sem critério pode elevar o custo do produto agrícola e contaminar o ambiente (Balota, 1997).

Vieira et al. (2004) demonstraram que a aplicação de fertilizantes nitrogenados no feijoeiro pode ser substituída por quantidades adequadas de lodo de esgoto e ficou também evidenciado que a aplicação de lodo pode estimular a nodulação e a fixação simbiótica de $\mathrm{N}_{2}$ pelas estirpes nativas de rizobio no feijoeiro.

O objetivo deste trabalho foi verificar o efeito da aplicação de adubação química de $\mathrm{N}$ e de doses de lodo de esgoto nos fatores produtivos do feijoeiro.

\section{MATERIAL E MÉTODOS}

O experimento foi conduzido na Fazenda Experimental São Manuel, pertencente à Faculdade de Ciências Agronômicas da UNESP de Botucatu, localizada no município de São Manuel a $22^{\circ} 25^{\prime}$ Latitude Sul, $48^{\circ} 34^{\prime}$ ' Longitude Oeste, com altitude de 750 metros.

Antecedendo a instalação do experimento, foram cultivados dois ciclos consecutivos de girassol semeados em dezembro de 2004 e novembro de 2005, respectivamente, seguidos por aplicações de lodo de esgoto e cultivo com trigo e triticale em parcelas subdivididas, em abril de 2006. Nos cultivos de trigo e triticale não foi aplicado lodo de esgoto. Em março de 2007 instalou-se a cultura da aveia, também com aplicação de lodo de esgoto, com o intuito de fornecer palha para o sistema de plantio direto. O cultivo do feijoeiro (Phaseoulus vulgaris L.) em sistema de semeadura direta, utilizando a variedade carioquinha, foi iniciado em dezembro de 2007, com aplicação de lodo compostado.

Foi adotado o delineamento experimental em blocos casualizados, e considerando-se uma mineralização de $30 \%$ do $\mathrm{N}$ proveniente do lodo compostado, definiram-se os seis tratamentos: T0 - sem adubação nitrogenada; T1 adubação química nitrogenada de acordo com Raij et al., (1997); T2 - 50\% adubação nitrogenada proveniente do lodo de esgoto e $50 \%$ na forma mineral; T3 - 100\% adubação nitrogenada proveniente do lodo de esgoto; T4 - 150\% adubação nitrogenada proveniente do lodo de esgoto; e T5 - 200\% adubação nitrogenada proveniente do lodo de esgoto. Cada parcela apresentou uma área de 100,8 metros quadrados (14 x 7,2m), com um espaço de $3 \mathrm{~m}$ entre parcelas do mesmo bloco. O espaço de um bloco a outro foi de 1,8 m. Cada tratamento teve quatro repetições.

Foi utilizado lodo de esgoto compostado com bagaço de cana, tendo a compostagem como principal finalidade a eliminação de patógenos.

O composto apresentou as características descritas na Tabela 1, sendo as analises realizadas conforme descrito por Lanarv (1988). 
Adotou-se o seguinte cálculo para determinação da dose de lodo de esgoto utilizada nos tratamentos: cada $100 \mathrm{~kg}$ de lodo de esgoto na base seca contém 2,4 kg de N. Considerando-se o teor de água de $50 \%$ na base seca, tem-se 1,2 \% de $\mathrm{N}$ na base úmida. Considerando-se a mineralização de $30 \%$ do N proveniente do lodo de esgoto (CONAMA, 2006), tem-se $0,36 \%$ de $\mathrm{N}$ mineralizado. Com base nesse ultimo percentual, as quantidades de lodo de esgoto destinadas para cada tratamento foram: T2 $10.000 \mathrm{~kg} \mathrm{ha}^{-1} ; \mathrm{T} 3-20.000 \mathrm{~kg} \mathrm{ha}^{-1} ; \mathrm{T} 4-30.000 \mathrm{~kg} \mathrm{ha}^{-1} ; \mathrm{T} 5$ $-40.000 \mathrm{~kg} \mathrm{ha}^{-1}$.

Foi executada calagem nas parcelas em que houve necessidade, utilizando-se a dose de $1,4 \mathrm{t} \mathrm{ha}^{-1}$ de calcário dolomítico com PRNT de $90 \%$, teor de $\mathrm{CaO}$ de $32 \%$ e MgO de $13 \%$. Essa dose foi baseada nas análises de solo. O cálculo dessa dose foi fundamentado na parcela que apresentou uma V\% menor, que foi aquela em que se aplicou uma maior dose de lodo de esgoto, conforme a Tabela 2. Nas parcelas que apresentaram V\% superior a $70 \%$ não foi feita a calagem.

Seis dias após a aplicação de calcário, foi efetuada a aplicação do composto de lodo de esgoto e de gliphosate.

A semeadura foi realizada 11 dias após a calagem. Usaram-se 13 sementes por metro, e espaçamento de $0,45 \mathrm{~m}$ entre linhas, totalizando 288.888 sementes em 1 ha. A profundidade de semeadura foi de $3 \mathrm{~cm}$, aproximadamente.

A adubação de semeadura foi efetuada com base na análise de solo da cultura anterior, utilizando como fonte de $\mathrm{N}$ a uréia, de $\mathrm{P}$ o superfosfato triplo e de K o cloreto de potássio. Foi realizada a adubação nitrogenada no tratamento $\mathrm{T} 1$ na dose de $10 \mathrm{~kg} \mathrm{ha}^{-1}$ de $\mathrm{N}$, empregando-se como fonte a uréia.

Aos 11 dias após a semeadura, ocorreu incidência de plantas de Avena strigosa Schreb., aveia preta com o Fluazifop- p-butil, na dose de 1,6 $\mathrm{L} \mathrm{ha}^{-1}$.

Foi realizada adubação nitrogenada de cobertura, aos 29 dias após a semeadura, nos tratamentos T1 e T2 nas doses de 60 e $35 \mathrm{~kg} \mathrm{ha}^{-1}$ de $\mathrm{N}$, respectivamente. A fonte utilizada foi a uréia.
Aos 36 dias após a semeadura, constatou-se o Raphanus raphanistrum L. (nabiça). Aplicou-se o Bentazone, na dose de $0,8 \mathrm{~L} \mathrm{ha}^{-1}$, em volume de calda de $250 \mathrm{~L} \mathrm{ha}^{-1}$. Aos 44 dias após a semeadura, foi aplicado o Chlorpyrikos, para controle de Pseudoplusia includens (Walker, 1857, lagarta). A dose utilizada foi de $0,5 \mathrm{~L} \mathrm{ha}^{-1} \mathrm{em}$ volume de calda de $200 \mathrm{~L} \mathrm{ha}^{-1}$. Aos 52 dias após a semeadura, foi empregado o Tebucanazole para o controle de Uromyces phaseoli (ferrugem), na dose de $0,3 \mathrm{~L} \mathrm{ha}^{-1}$, em volume de calda de $200 \mathrm{~L} \mathrm{ha}^{-1}$. Aos 66 dias após a semeadura, foi utilizado o Metamidophós para o controle de Deois flavopicta (Stall, 1954, Homoptera, Cercopidae, cigarrinha das postagens), na dose utilizada de $0,3 \mathrm{~L} \mathrm{ha}^{-1}$, e o volume de calda de $200 \mathrm{~L} \mathrm{ha}^{-1}$.

A colheita foi realizada 95 dias após a semeadura. As características avaliadas foram as seguintes: número de plantas por hectare; número de vagens por hectare; rendimento de matéria seca de folhas, caules e raizes $\left(\mathrm{kg} \mathrm{ha}^{-1}\right)$; rendimento de matéria seca de vagens $\left(\mathrm{kg} \mathrm{ha}^{-1}\right)$; rendimento de matéria seca total $\left(\mathrm{kg} \mathrm{ha}^{-1}\right)$; rendimento de grãos $\left(\mathrm{kg} \mathrm{ha}^{-1}\right)$; massa de 1.000 grãos.

Para a determinação de número de plantas ha ${ }^{-1}$ foram coletadas cinco amostras de $1 \mathrm{~m}$ em cada parcela. Para se obter a quantidade de vagens em 1 ha foi multiplicado o número de vagens por planta pelo número de plantas em 1 ha. Para se obter o rendimento de matéria seca foi multiplicado o peso de matéria seca pelo número de plantas em 1 ha. Na determinação do rendimento de grãos em 1 ha foi multiplicado o valor de número de plantas em 1 ha pela massa de grãos por planta, corrigindo-se o valor obtido para $13 \%$ de umidade. A massa de 1.000 grãos foi determinada pela coleta, contagem e pesagem de 8 amostras de 100 grãos por parcela experimental. A média foi multiplicada por 10 para obter a massa de 1000 grãos (Brasil, 1992).

Foi instalado no local do ensaio um pluviômetro para medir a precipitação. Durante o ciclo da cultura houve uma precipitação total de $733 \mathrm{~mm}$, como se observa na Figura 1. Os dados de temperatura mínima média, média e

Tabela 1. Características químicas do composto de lodo de esgoto utilizado ${ }^{1}$

\begin{tabular}{|c|c|c|c|c|c|c|c|c|c|c|c|c|c|c|c|}
\hline $\mathbf{N}$ & $\mathbf{P}_{2} \mathbf{O}_{5}$ & $\mathbf{K}_{2} \mathbf{O}$ & Umid. & MO & C & $\mathbf{C a}$ & Mg & $\mathbf{S}$ & $\mathbf{N a}$ & $\mathrm{Cu}$ & $\mathrm{Fe}$ & Mn & $\mathbf{Z n}$ & \multirow[t]{2}{*}{$\mathbf{C} / \mathbf{N}$} & \multirow[t]{2}{*}{ pH } \\
\hline \multicolumn{9}{|c|}{ dag kg-1 } & \multicolumn{5}{|c|}{$\mathrm{mg} \mathrm{kg}^{-1}$} & & \\
\hline 2,4 & 2,0 & 0,4 & 50 & 55,0 & 31,0 & 1,9 & 0,3 & 1,6 & 1340 & 304 & 23250 & 472 & 3750 & $13 / 1$ & 6,6 \\
\hline
\end{tabular}

${ }^{1}$ Concentrações totais de nutrientes determinadas no extrato da digestão nitricoperclorica.

Tabela 2. Características químicas do solo da parcela de menor saturação por bases

\begin{tabular}{|c|c|c|c|c|c|c|c|c|c|c|c|}
\hline Prof. & pH & M.O. & $\mathbf{P}$ (res.) & $\mathbf{H}+\mathbf{A l}$ & $\mathbf{A \mathbf { l } ^ { + 3 }}$ & $\mathbf{K}^{+}$ & $\mathrm{Ca}^{+2}$ & $\mathbf{M g}^{+2}$ & S B & $\mathbf{T}$ & $\mathbf{V}$ \\
\hline $\mathrm{cm}$ & $\mathrm{CaCl}_{2}$ & $\mathrm{gdm}^{-3}$ & $\overline{\mathrm{mg} \mathrm{dm}^{-3}}$ & \multicolumn{7}{|c|}{$\mathrm{mmol}_{\mathrm{c}} \mathrm{dm}^{-3}$} & $\%$ \\
\hline $0-20$ & 4,7 & 30 & 23 & 28 & - & 2,2 & 17 & 5 & 24 & 53 & 46 \\
\hline
\end{tabular}

$\mathrm{pH}$ em $\mathrm{CaCl}_{2}$ relação 1:2,5; M.O.- método de Walkley-Black; H+Al - método potenciometrico (solução tampão SMP); Ca, Mg, K extrator, resina trocadora de íons; $\mathrm{Al}$ - extrator, $\mathrm{KCl}$; $\mathrm{SB}=$ Soma de bases; $\mathrm{T}=\mathrm{SB}+\mathrm{H}+\mathrm{Al} ; \mathrm{V}=\mathrm{SB} / \mathrm{T} * 100$. 

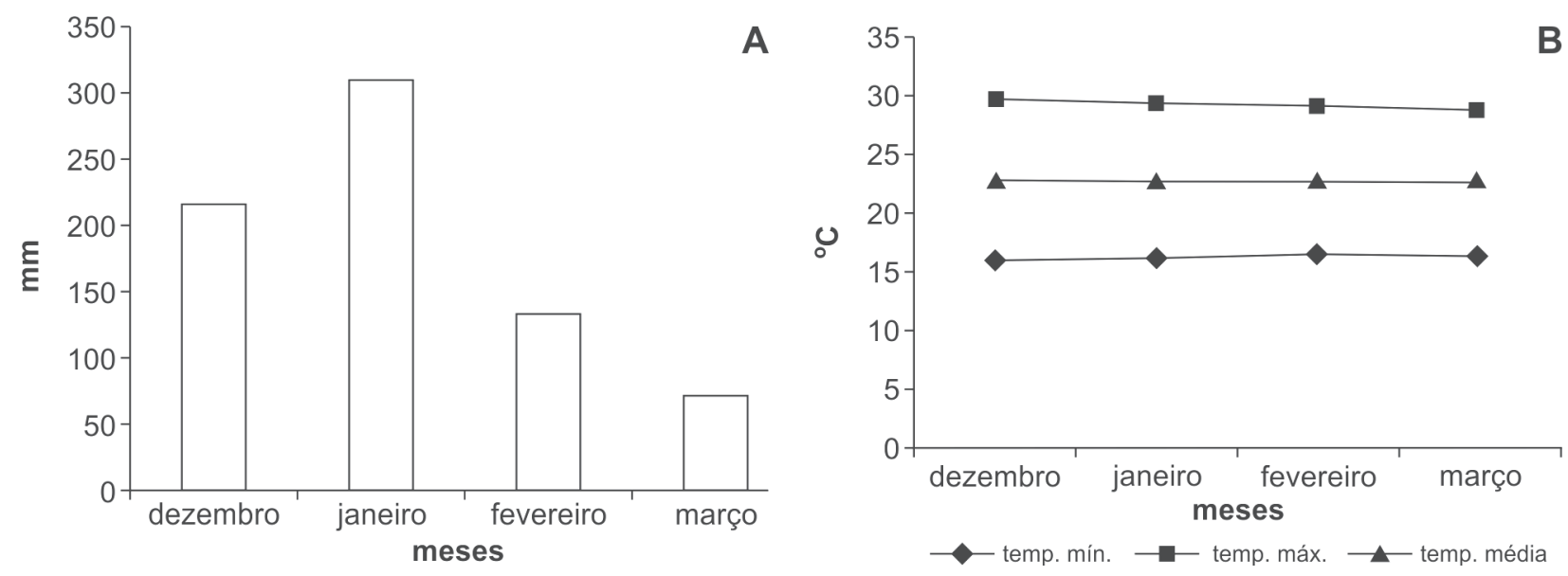

Figura 1. Precipitação pluviométrica (A) e temperatura mínima média, média e máxima média (B) observadas durante o ciclo do feijoeiro, no período de dezembro de 2007 a março de 2008. Fazenda Experimental São Manuel, FCA, UNESP, Botucatu.

máxima média foram fornecidos pela estação climatológica da fazenda experimental de São Manuel, pertencente ao Departamento Recursos Naturais, Área de Ciências Ambientais da Faculdade de Ciências Agronômicas de Botucatu.

Os dados foram submetidos a análise de variância e as média comparadas pelo teste de Duncan 5\%, utilizandose o programa de estatística SAEG (1993). Para os tratamentos T0, T3, T4 e T5, que se constituíram de doses crescentes de lodo, foi efetuada análise de regressão.

\section{RESULTADOS E DISCUSSÃO}

Observa-se na Tabela 3 que a média do estande geral foi de 178.023 plantas ha ${ }^{-1}$, que representa $61 \%$ do número de sementes semeadas. O número final de plantas não variou significativamente entre os tratamentos.

Tabela 3. Número de plantas por hectare e número de vagens por planta de feijão cultivado com diferentes doses de $\mathrm{N}$ mineral e doses crescentes de lodo de esgoto compostado

\begin{tabular}{lcc}
\hline Tratamentos & $\begin{array}{c}\text { Número de } \\
\text { plantas ha-1 }^{-1}\end{array}$ & $\begin{array}{c}\text { Número de vagens } \\
\text { por planta }\end{array}$ \\
\hline T0 & $189.627,7$ & $7,86 \mathrm{c}$ \\
T1 & $179.257,5$ & $9,45 \mathrm{bc}$ \\
T2 & $174.813,1$ & $10,89 \mathrm{ab}$ \\
T3 & $176.294,5$ & $11,27 \mathrm{ab}$ \\
T4 & $161.479,9$ & $11,73 \mathrm{a}$ \\
T5 & $186.664,8$ & $11,01 \mathrm{ab}$ \\
\hline F & 1,0 & 5,52 \\
Média & $178.022,9$ & 10,37 \\
\hline CV & 11,19 & 13,29 \\
\hline
\end{tabular}

Médias seguidas pelas mesmas letras não diferem entre si pelo teste de Duncan $5 \%$ de probabilidade. T0 - sem N, T1 -100\% AM, T2 $-50 \% \mathrm{AM}+50 \% \mathrm{LE}, \mathrm{T} 3-100 \%$ LE, T4 - 150\% LE, T5 - $200 \%$ LE,. AM, - Adubação mineral; LE - Lodo de esgoto
Quanto ao número de vagens por planta, o do tratamento T4 foi superior ao daqueles em que não foi aplicado lodo (T0 e T1). Com o aumento da dose de lodo compostado aumentou o número total de vagens por ha como mostra a Figura 2. Coelho et al., (2001) constatou que a adubação com $40 \mathrm{~kg} \mathrm{ha}^{-1}$ de $\mathrm{N}$ promoveu incremento de três vagens por planta em relação ao tratamento sem aplicação de N, com isso obteve-se aumento de $64 \%$ na produtividade.

Verifica-se em relação ao rendimento de matéria seca de folhas, caules e raízes que o tratamento que não recebeu $\mathrm{N}$ foi inferior aos tratamentos T1 e T5 conforme está apresentado na Tabela 4. O aumento da dose de lodo proporcionou o aumento linear nesta característica, como se observa na Figura 3. Cada tonelada de lodo aplicado aumentou em $8,4 \mathrm{~kg}$ a massa de matéria seca de folhas, caules e raizes.

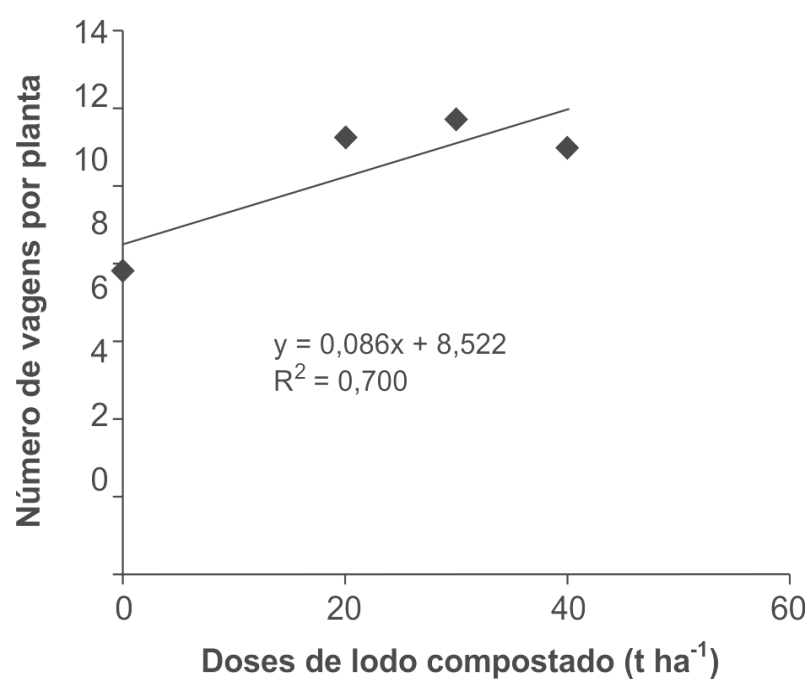

Figura 2. Número de vagens do feijoeiro por planta em função da dose de lodo de esgoto compostado.

Rev. Ceres, Viçosa, v. 59, n.1, p. 118-124, jan/fev, 2012 
Observa-se na Tabela 4 que para o rendimento de matéria seca das vagens o tratamento $\mathrm{T} 2$ foi superior aos $\mathrm{T} 0$, T1 e T3 e T4. Com o aumento da dose de lodo compostado, cresceu linearmente o rendimento de matéria seca, conforme se observa na Figura 3. Cada tonelada de lodo aumentou em 4,6 kg a produção de vagens.

Em relação ao rendimento de matéria seca total os tratamentos T1, T2 e T5 foram superiores ao tratamento que não recebeu N (T0 - Tabela 4). O aumento da dose de lodo compostado promoveu aumentos lineares no rendimento de matéria seca (Figura 3). Cada 1.000 kg de lodo de esgoto compostado aumentaram em $13 \mathrm{~kg}$ a produção de matéria seca total. Vieira et al. (2005), verificou que o feijão tratado com lodo de esgoto apresentou produtividade de matéria seca superior ao que recebeu adubação mineral, considerando a mesma dose de N.

Observa-se na Tabela 5 que o tratamento T5 foi superior aos $\mathrm{T} 0 \mathrm{e} \mathrm{T} 1$. $\mathrm{O}$ tratamento $\mathrm{T} 0$ foi inferior a todos

Tabela 4. Rendimentos de massa de matéria seca de feijão cultivado com diferentes doses de $\mathrm{N}$ mineral e doses crescentes de lodo de esgoto compostado

\begin{tabular}{lccc}
\hline \multirow{2}{*}{ Tratamentos } & Folha + caule + raiz & Vagem & Total \\
\cline { 2 - 4 } & & kg ha $^{-\mathbf{1}}$ & $1297,17 \mathrm{~b}$ \\
T0 & $790,44 \mathrm{~b}$ & $506,74 \mathrm{c}$ & $1743,95 \mathrm{a}$ \\
T1 & $1.156,55 \mathrm{a}$ & $587,40 \mathrm{bc}$ & $1762,22 \mathrm{a}$ \\
T2 & $1.005,86 \mathrm{ab}$ & $756,36 \mathrm{a}$ & $1499,51 \mathrm{ab}$ \\
T3 & $915,80 \mathrm{ab}$ & $583,71 \mathrm{bc}$ & $1486,37 \mathrm{ab}$ \\
T4 & $896,14 \mathrm{ab}$ & $590,23 \mathrm{bc}$ & $1896,16 \mathrm{a}$ \\
T5 & $1.183,35 \mathrm{a}$ & $712,81 \mathrm{ab}$ & 2,63 \\
F & 2,32 & 5,10 & 1614,23 \\
Média & 991,36 & 622,87 & 17,02 \\
\hline CV & 20,49 & 13,22 & \\
\hline
\end{tabular}

Médias seguidas pelas mesmas letras não diferem entre si pelo teste de Duncan 5\% de probabilidade. T0 - sem N, T1 -100\% AM, T2 $50 \% \mathrm{AM}+50 \% \mathrm{LE}, \mathrm{T} 3-100 \%$ LE, T4 - 150\% LE, T5 - 200\% LE,. AM - Adubação mineral; LE - Lodo de esgoto
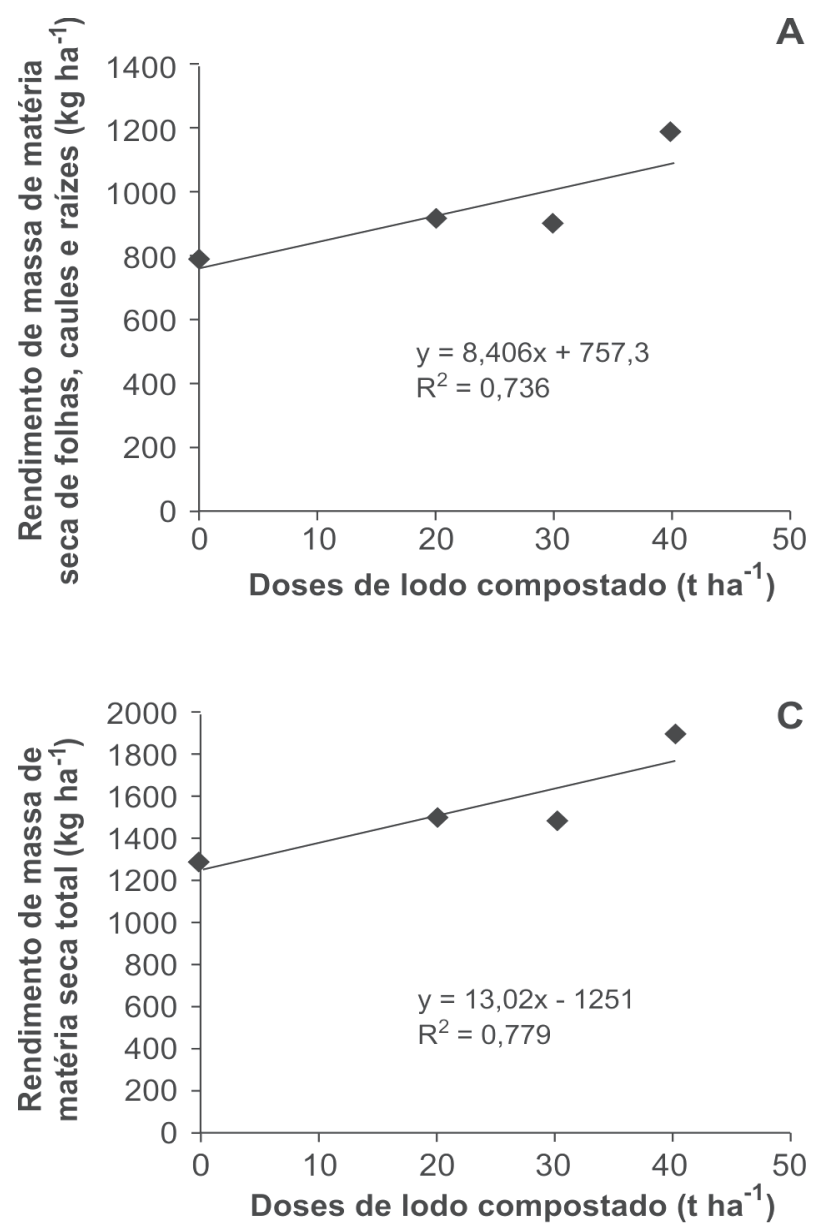

A

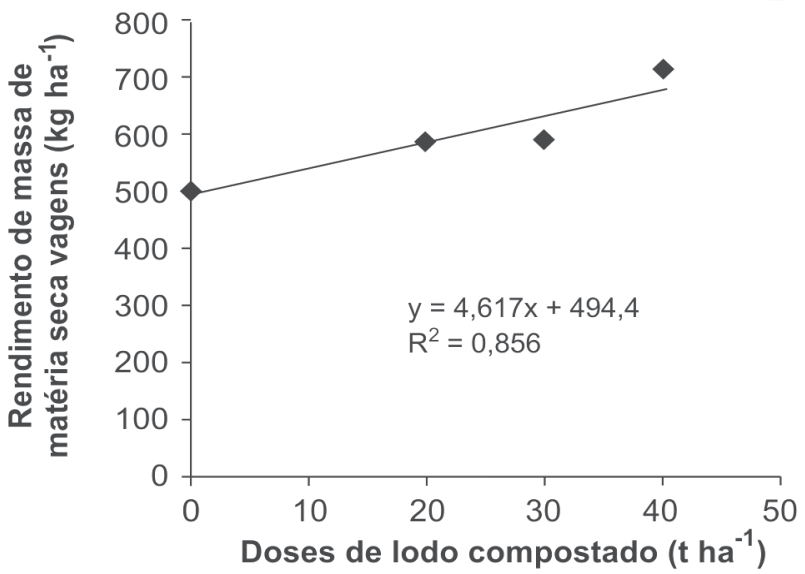

Figura 3. Rendimento de massa de matéria seca de folhas, caules e raizes (A), vagens (B) e total (C) do feijoeiro em função da dose de lodo compostado.

Rev. Ceres, Viçosa, v. 59, n.1, p. 118-124, jan/fev, 2012 

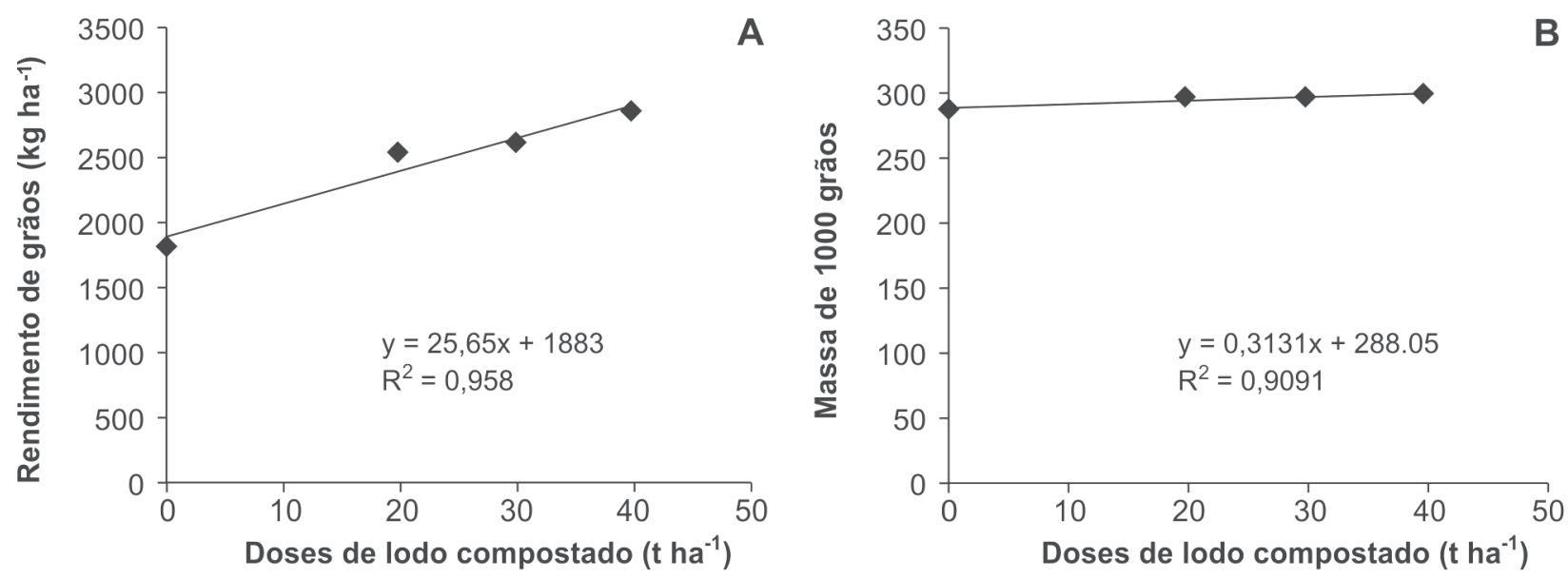

Figura 4. Rendimento de grãos (A) e massa de 1.000 grãos (B) do feijão em função da dose de lodo compostado

Tabela 5. Rendimento de grãos e massa de 1.000 sementes de feijão cultivado com diferentes doses de $\mathrm{N}$ mineral e doses crescentes de lodo de esgoto compostado

\begin{tabular}{lcc}
\hline Tratamentos & $\begin{array}{c}\text { Rendimento } \\
\text { de grãos } \\
\mathbf{k g ~ h a}^{-1}\end{array}$ & $\begin{array}{c}\text { Massa de } \\
\text { mil sementes } \\
\mathbf{g}\end{array}$ \\
\hline T0 & $1.823 \mathrm{c}$ & $286,9 \mathrm{~b}$ \\
T1 & $2.297 \mathrm{~b}$ & $289,1 \mathrm{ab}$ \\
T2 & $2.426 \mathrm{ab}$ & $290,3 \mathrm{ab}$ \\
T3 & $2.537 \mathrm{ab}$ & $296,8 \mathrm{ab}$ \\
T4 & $2.622 \mathrm{ab}$ & $297,1 \mathrm{ab}$ \\
T5 & $2.865 \mathrm{a}$ & $299,6 \mathrm{a}$ \\
\hline F & 5,12 & 1,94 \\
Média & 2.428 & 293,3 \\
\hline CV & 12,86 & 2,53 \\
\hline
\end{tabular}

Médias seguidas pelas mesmas letras não diferem entre si pelo teste de Duncan 5\% de probabilidade. T0 - sem N, T1 -100\% AM, T2 - $50 \% \mathrm{AM}+50 \% \mathrm{LE}, \mathrm{T} 3-100 \% \mathrm{LE}, \mathrm{T} 4-150 \%$ LE, T5 - 200\% LE,. AM - Adubação mineral; LE - Lodo de esgoto

os tratamentos em relação ao rendimento de grãos. Dinis (1995), observou que a adubação nitrogenada com $40 \mathrm{~kg} \mathrm{ha}^{-1}$ na semeadura e em cobertura se mostrou eficiente na cultura do feijoeiro, aumentando o número de vagens por planta e o peso das sementes, resultando em acréscimo de produtividade da ordem de 19 a $39 \%$. Ocorreu aumento no rendimento de grãos com o aumento da dose de lodo compostado, conforme mostra a Figura 4. Cada $1000 \mathrm{~kg}$ de lodo de esgoto promoveu acréscimos de 25,63 kg. Gardioli \& Fortes Neto, (2004) obtiveram aumento quadrático no rendimento de grãos no feijão-preto em razão da dose de lodo de esgoto. Meira et al. (2005), testando a adubação do feijoeiro com doses de $0,40,80,120,160,200,240 \mathrm{~kg}$ ha ${ }^{1}$ de N, obtiveram produtividade 3.024, 3.372, 3.510, 3.470, $3.639,3.539,3.516 \mathrm{~kg} \mathrm{ha}^{-1}$ respectivamente. Farinelli et al (2006), obtiveram aumento de produtividade de grãos de feijoeiro até a dose de $172 \mathrm{~kg} \mathrm{ha}^{-1}$ de N. Deschamps
\& Favaretto (1997) observaram que o lodo de esgoto pode ser utilizado como adubação orgânica, substituindo $100 \%$ a quantidade de $\mathrm{N}$ recomendada sem prejuízo no rendimento do feijoeiro.

Quanto à massa de 1.000 grãos, observa-se na Tabela 5 que o tratamento T5, que recebeu a maior dose de lodo foi superior ao tratamento que não recebeu N (T0). Houve aumento linear em razão da dose de lodo compostado (Figura 4), tendo cada $1.000 \mathrm{~kg}$ de lodo aumentado em 0,31 g a massa de 1.000 grãos do feijoeiro.

\section{CONCLUSÕES}

O aumento da dose de lodo de esgoto promoveu incremento no número de vagens, rendimento de matéria seca, rendimento de grãos e na massa de 1000 grãos.

$\mathrm{O} \mathrm{N}$ promoveu o aumento do rendimento de grãos e da massa de matéria seca do feijoeiro.

\section{REFERÊNCIAS}

Balota EL (1997) Alterações microbiológicas em solos cultivados sob o plantio direto. In: Peixoto, RTG, Ahrens, DC, Samaha, MJ (Eds.) Plantio direto: o caminho para a agricultura sustentável. Ponta Grossa, IAPAR, p. 222-231.

Betiol W. \& Camargo OA (2006) Impacto ambiental do uso agrícola do lodo de esgoto. In: Spadoto C. \& Ribeiro W. Gestão de resíduos na agricultura e agroindústria. Botucatu, FEPAF. p.181-204.

Boeira RC (2004) Uso do lodo de esgoto como fertilizante orgânico: disponibilização de nitrogênio em solos tropicais. Jaguariuna, Embrapa Meio Ambiente. 3p. (Comunicado Técnico 12).

Brasil (1992) Regras para análise de sementes. Brasília, Ministério da Agricultura e Reforma Agrária. 365 p.

Coelho FC, Freitas P, Monerat PH \& Dornelles MS (2001) Efeito sobre a cultura do feijão das adubações com nitrogênio e molibdênio e do manejo de plantas daninhas. Revista Ceres, 278:455-467.

Companhia Nacional do Meio Ambiente. Resolução no 375/2006. Disponível em: <httb://www.mma.gov.br/post/conama/legiano/ >. Acessado em: 10 de outubro de 2006. 
Deschamps C \& Favoretto N (1997) Efeito do lodo de esgoto complementado com fertilizante mineral na produtividade e desenvolvimento da cultura do feijoeiro e do girassol. Sanare Revista técnica da Sanepar, 8:33-38.

Dinis AR (1995) Resposta da cultura do feijão (Phaseolus vulgaris L.) à aplicação de nitrogênio (semeadura e cobertura) e de molibdênio foliar. Dissertação de mestrado. Universidade Federal de Lavras, Lavras, 60p.

Farinelli R, Lemos LB, Penario FG, Egea MM \& Gasparoto MG. (2006) Adubação nitrogenada de cobertura no feijoeiro, plantio direto e convencional. Pesquisa Agropecuária Brasileira, 41:307-312.

Gardioli JL \& Fortes Neto P (2004) Rendimento de milho e feijão preto cultivado em solos acrescidos de lodo de esgoto. Sanare Revista técnica da Sanepar, 21:53-58.

Lanarv (1988) Análise de corretivos, fertilizantes e inoculantes: métodos oficiais. Brasília, Ministério da Agricultura, 104p.

Meira FA, Sá ME, Buzetti S \& Arf O (2005) Doses e épocas de aplicação de nitrogênio no feijoeiro irrigado cultivado em plantio direto. Pesquisa Agropecuária Brasileira, 40:383-388.

Munhoz, RO (2001) Disponibilidade de fósforo para o milho em solo que recebeu lodo de esgoto. Dissertação de mestrado. Instituto Agronômico de Campinas, Campinas, 74p.

Oliveira, FC (2000) Disposição de resíduos orgânico e compostos de lixo urbano num latossolo vermelho amarelo cultivado com cana-de-açúcar. Tese de Doutorado. Escola Superior de Agricultura "Luiz de Queiroz", Piracicaba, 247p.
Pegorini ES, Andreoli CV, Souza ML \& Ferreira A (2003) Qualidade do lodo de esgoto utilizado na reciclagem agrícola na região metropolitana de Curitiba - PR. In: I Simposio Latino Americano de biossolido, São Paulo. Anais, 11p.

Raij BV, Cantarella H, Quaggio JA \& Furlani AMC (1997) Recomendações de adubação e calagem para o Estado de São Paulo. $2^{\mathrm{a}}$ ed. Campinas, IAC, 198p. (IAC. Boletim Técnico, 100).

Rocha, TR (1998) Utilização do lodo de esgoto na agricultura: um estudo de caso para as bacias hidrográficas dos rios Dissertação de Mestrado. Escola Superior de Agricultura "Luiz de Queiroz", Universidade Estadual de São Paulo, Piracicaba, 70p.

Sabey, BR (1980) The use of sewage as a fertilizer. In: Bewick, M.W. Handbook of organic waste conversion. Van Nostrand Reinhold, 72:102-107.

SAEG (1993) Sistema para análises estatísticas e genéticas, Viçosa, UFV/CPD.

Vieira RF, Tsai SM \& Teixeira MA (2004) Efeito do lodo de esgoto no crescimento e fixação simbiótica do $\mathrm{N}_{2}$ em feijoeiro (Phaseolus vulgaris L.). Jaguariúna, Embrapa Meio Ambiente. 18p. (Boletim de pesquisa e desenvolvimento)

Vieira RF, Tsai SM \& Teixeira MA. (2005) Nodulação e fixação simbiótica de nitrogênio em feijoeiro com estirpe nativa de rizóbio, em solos tratados com lodo de esgoto. Pesquisa Agropecuária Brasileira, 40:1047-1050. 